\title{
Os efeitos do Programa Bolsa Família sobre a duração do emprego formal dos indivíduos de baixa renda
}

\author{
Danilo Braun Santos \\ Universidade Federal de São Paulo / Escola Paulista de Política, Economia e Negócios \\ Osasco / SP — Brasil
}

\author{
Alexandre Ribeiro Leichsenring \\ Universidade de São Paulo / Escola de Artes, Ciências e Humanidades \\ São Paulo / SP — Brasil
}

Naercio Menezes Filho

Insper Instituto de Ensino e Pesquisa

Universidade de São Paulo / Departamento de Economia

São Paulo / SP — Brasil

Wesley Mendes-Da-Silva

Fundação Getulio Vargas / Escola de Administração de Empresas de São Paulo

São Paulo / SP — Brasil

Neste artigo utilizamos microdados do Cadastro Único combinados com dados da Relação Anual de Informações Sociais (Rais) para examinar a duração do emprego entre indivíduos de famílias beneficiárias do Programa Bolsa Família. Para tanto, estimamos modelos de riscos proporcionais de Cox para comparar a duração no emprego entre beneficiários e não beneficiários do programa utilizando uma base de dados com mais de três milhões de indivíduos pertencentes a famílias de baixa renda. Os resultados sugerem que o risco de desligamento do emprego para os beneficiários do Programa Bolsa Família é entre 7\% e 10\% menor do que para os não beneficiários. Modelos paramétricos também foram ajustados para verificação de robustez, produzindo resultados equivalentes aos do modelo de Cox. Em todos os casos, a participação no programa foi observada por meio de uma covariável variando no tempo, extraída diretamente das folhas de pagamento do programa.

Palavras-chave: emprego; oferta de trabalho; análise de duração; riscos proporcionais; bolsa família.

\section{Los efectos del Programa Bolsa Familia sobre la duración del empleo formal de los individuos de bajos ingresos}

En este artículo utilizamos microdatos del registro nacional de personas pobres (Cadastro Único) combinados con datos de la Relación Anual de Informaciones Sociales (Rais) para examinar la duración del empleo entre individuos de familias beneficiadas por el Programa Bolsa Família. Por lo tanto, se estima un modelo de riesgos proporcionales de Cox para comparar la duración del empleo entre beneficiarios y no beneficiarios del programa, utilizando una base de datos con más de tres millones de individuos pertenecientes a familias de bajos recursos. Los resultados sugieren que el riesgo de extinción de empleo para los beneficiarios del Programa Bolsa Família es entre un $7 \%$ y un $10 \%$ inferior a la de los no usuarios. Modelos paramétricos también fueron ajustados para verificación de robustez, produciendo resultados equivalentes a los del modelo de Cox. En todos los casos, la participación en el programa fue observada a través de una covariable variando en el tiempo, extraída directamente de la nómina del programa.

Palabras clave: empleo; oferta de trabajo; análisis de duración; riesgos proporcionales; bolsa familia. 


\section{The impact of the Bolsa Família Program on the duration of formal employment of people with low income}

This article uses microdata from the national registry of the poor and vulnerable population (Cadastro Único) and the Annual Social Information Report (Rais) to examine the duration of employment of families receiving benefits from the Bolsa Família Program. Regarding this goal, Cox proportional hazards models were estimated to compare the length of employment between beneficiaries and non-beneficiaries of the program using a database of more than three million people. Results indicate that the risk of leaving the job among beneficiaries of the Bolsa Família Program is 7\% to $10 \%$ lower than that of non-beneficiaries. Parametric models were also adjusted to verify robustness, producing results equivalent to those of the Cox model. In all cases, participation in the program was observed through a covariate varying in time, extracted directly from the program's payroll.

Keywords: employment; labour supply; duration analysis; proportional hazard; bolsa família.

\section{INTRODUÇÃO}

Para a Organização Internacional do Trabalho (OIT), o trabalho é a via fundamental para a superação da pobreza, das desigualdades e da exclusão social, e uma das formas mais diretas pela qual o desenvolvimento econômico pode favorecer o bem-estar das pessoas. O mercado de trabalho formal, além de manter famílias fora da pobreza, também oferece acesso a direitos e garantias para trabalhadores, e seguridade social. A precariedade da inserção de trabalhadores de baixa renda no mercado formal de trabalho acaba por agravar a volatilidade de renda e a alta rotatividade no emprego, que caracterizam esse estrato da população.

Nesse contexto, é fundamental compreender a dinâmica da participação das populações economicamente vulneráveis no mercado formal de trabalho. A construção desse tipo de conhecimento pode sugerir a implantação de reformas no sistema de proteção social vigente, de maneira a garantir a promoção do bem-estar da população e sua adequação às diferentes realidades socioeconômicas e estágios do ciclo de vida.

Pode-se esperar que um programa com transferências monetárias induza uma redução na oferta de trabalho, uma vez que diminui a necessidade econômica de trabalhar (efeito renda). Atrelado a isso, junta-se o fato de que programas focalizados no público de baixa renda possam induzir um desincentivo ao emprego formal, uma vez que o critério de elegibilidade baseado em renda familiar pode implicar a diminuição da oferta de trabalho de membros da família de modo a evitar que o teto estabelecido seja ultrapassado. Essa suposta acomodação tem sido tratada na literatura por efeito preguiça.

Por outro lado, o fato de que um programa de transferência de renda seja condicionado à frequência escolar tende a implicar, para crianças, aumento na escolarização e redução do tempo investido em outras atividades, notadamente em trabalho e lazer. Uma vez que há diminuição da oferta de trabalho por crianças, os adultos devem prover substituição de trabalho antes executado por elas.

Do ponto de vista da teoria econômica, portanto, é ambíguo o efeito de um programa de transferência de renda condicionada na oferta de trabalho dos beneficiários. Além de os efeitos dependerem das preferências individuais, as análises deveriam levar em conta os diversos membros da família, que possuem restrições orçamentárias cruzadas. Trata-se, assim, de uma questão eminentemente empírica. Uma discussão mais detalhada das limitações da análise microeconômica para a avaliação de impacto dos programas de transferência de renda condicionada é apresentada em Oliveira e Soares (2012). 
Há várias estratégias empíricas para se investigar o efeito de um programa de transferência de renda na oferta de trabalho. No cenário ideal, é desejável contar com um desenho experimental onde a atribuição do benefício é aleatorizada, ou seja, o tratamento é atribuído de maneira aleatória para uma fração da população elegível (grupo tratamento). Se a escolha dos indivíduos que receberão o benefício é aleatória, os grupos tratamento e controle, com tamanhos suficientemente grandes, deverão ter características uniformemente semelhantes. Nesse caso, qualquer diferença observada nos resultados poderá ser atribuída aos efeitos da participação no programa.

Infelizmente, esse contexto é muito raro em estudos nas ciências sociais. O critério de elegibilidade do Programa Bolsa Família é fundamentalmente baseado na renda familiar per capita (declarada no Cadastro Único de Políticas Sociais do Governo Federal), o que não corresponde ao desenho experimental com aleatorização. O presente caso é um típico estudo observacional, demandando métodos não experimentais. Geralmente, estudos baseados nesses métodos empregam dados individuais para controlar as diferenças entre os grupos controle e tratamento, utilizando, tipicamente, médias condicionadas a uma série de características individuais observáveis.

O presente estudo dedica-se à especificação de um modelo particular de regressão para identificar o efeito do Programa Bolsa Família na duração dos vínculos de trabalho no mercado formal, abordagem ainda inexplorada nas publicações sobre o tema. Entre outros artifícios, a caracterização do status de beneficiário do programa é feita por meio de uma covariável variando no tempo, permitindo a identificação dos meses em que a família estava efetivamente beneficiária do programa e dos meses em que ela se encontrava desligada. E utiliza um conjunto abrangente de dados: i) o Cadastro Único para Programas Sociais do Governo Federal (CadÚnico), do Ministério do Desenvolvimento Social e Combate à Fome, considerado um censo da população de baixa renda no Brasil, com cerca de 80 milhões de observações; ii) a Relação Anual de Informações Sociais (Rais), do Ministério do Trabalho e Emprego, que oferece informações de todo o universo de empregados com vínculos formais no Brasil, ao redor de 50 milhões de observações/ano; e iii) as folhas de pagamento do Programa Bolsa Família (PBF), incluindo todos os meses desde seu início, em 2004, e conta com as, aproximadamente, 21 milhões de famílias que eram (em 2011) ou foram em algum momento anterior beneficiárias do programa.

O objetivo deste estudo é, portanto, comparar a participação no mercado formal de trabalho de beneficiários do PBF com os indivíduos não beneficiários inscritos no Cadastro Único. O artigo está estruturado da seguinte forma: a seção 2 faz uma breve descrição do Programa Bolsa Família e das condições do emprego no Brasil, além de apresentar a literatura acerca desses temas, relevantes para esse trabalho; a seção 3 descreve as bases de dados utilizadas e a metodologia empregada; na seção 4 os resultados do trabalho são apresentados e discutidos e, por fim, a seção 5 conclui.

\section{CONTEXTO DE CAMPO}

\subsection{O PROGRAMA BOLSA FAMÍLIA}

O Programa Bolsa Família (PBF) foi instituído pelo governo federal do Brasil pela Lei no 10.836 , de 9 de janeiro de 2004. Segundo o Ministério do Desenvolvimento Social e Combate à Fome (MDS), o $\mathrm{PBF}$ é um programa de transferência direta de renda que beneficia famílias em situação de pobreza 
e de extrema pobreza. Em 2011, situação de pobreza era caracterizada por uma renda familiar per capita entre $\mathrm{R} \$ 70$ e $\mathrm{R} \$ 140$ mensais e de extrema pobreza por uma renda familiar per capita inferior a R\$ 70 mensais.

São condições necessárias para uma família participar do programa o enquadramento na situação de extrema pobreza ou o enquadramento na situação de pobreza, desde que tenham em sua composição gestantes, nutrizes (mães que estão amamentando) ou crianças e adolescentes com idade entre 0 e 17 anos.

Além disso, exige-se frequência escolar mínima de 85\% para as crianças com idades de seis a 15 anos e, para as menores, que sejam levadas regularmente aos postos de saúde mantendo suas carteiras de vacinação em dia. As condicionalidades e ações complementares ligadas ao programa compõem objetivos de longo prazo de construção de capital humano visando interromper a transmissão geracional da pobreza (Britto, 2005; Lindert et al. 2007).

Com relação aos impactos dos programas de transferência de renda de modo geral, Marshall e Hill (2014) revisam a literatura e observam efeitos no aumento da frequência escolar e, consequentemente, aumento da oferta de trabalho por parte das mulheres. Ao dirigir a transferência de recursos para a mãe, ao invés do pai, esses programas produzem níveis mais elevados de bem-estar para as crianças, e ainda contribuem para o empoderamento das mulheres beneficiárias, que passam a ter papel mais relevante na tomada de decisões do agregado familiar (Britto, 2005). A diminuição do trabalho infantil também é consenso para os programas de transferência de renda condicionados (De Hoop e Rosati, 2014).

Há considerável consenso, também, do impacto positivo do Programa Bolsa Família sobre a frequência escolar (Araújo et al., 2010; Oliveira e Soares, 2012; Soares et al., 2010; Chitolina et al., 2016; Ferro et al., 2010). No entanto, Oliveira e colaboradores (2007) avaliaram que o PBF não teve impacto sobre a vacinação de crianças. Como o programa criou maior consciência sobre a necessidade de acessar os serviços de saúde pública e obter imunização infantil, por meio da condicionalidade imposta, a ausência desse impacto sugere obstáculos do lado da oferta desses serviços (Soares et al., 2010).

Britto (2005) aponta ainda outros dois efeitos colaterais: i) incentivos para o registro civil, uma vez que documentos oficiais são necessários para as mães recolherem o benefício; e ii) maior acesso ao sistema financeiro, pois os beneficiários recebem as transferências via cartões magnéticos de contas bancárias individuais.

Oliveira e Soares (2012) fazem uma compilação de diversos artigos focados na investigação de um possível efeito preguiça. O estudo resume resultados de artigos sobre a oferta de trabalho da população beneficiária de programas de transferência de renda condicionados, baseados em diversas pesquisas amostrais nacionais. A oferta de trabalho é medida a partir de três prismas: participação no mercado de trabalho, jornada de trabalho e providências para conseguir emprego. A conclusão do estudo aponta que

programas de transferência de renda condicionada possuem impactos pequenos sobre o mercado de trabalho, e alguns destes impactos - como a redução da jornada de trabalho das mães e o aumento na probabilidade de trabalho para certos grupos - são positivos ou não necessariamente ruins. Pode-se afirmar, com muito embasamento, que não existe constatação empírica que sustente a hipótese de efeito preguiça. [Oliveira e Soares, 2012:30] 
Além de Oliveira e Soares (2012), uma gama de outros estudos aponta inexistência de efeito significativo do Bolsa Família na oferta de trabalho de familiares adultos, seja do ponto de vista estatístico, seja do grau de magnitude (Ferro et al., 2010; Chitolina et al., 2016; Foguel e Barros, 2010; Soares, 2012). Em sua maior parte, os achados significativos estão relacionados com a redução de horas trabalhadas, especialmente por mães e mulheres.

Utilizando dados da Pesquisa Nacional por Amostra de Domicílios (PNAD), Tavares (2010) estudou o efeito do PBF sobre a oferta de trabalho das mães, grupo que, teoricamente, deveria ser mais impactado pelo recebimento do benefício, uma vez que possui maior salário reserva devido aos cuidados domésticos e tempo dedicado aos filhos.

A autora encontra um efeito renda associado ao valor do benefício (quanto maior a transferência recebida, menor o engajamento da mãe no mercado de trabalho) e um efeito substituição (as mães ampliam sua oferta de trabalho para compensar a redução da oferta dos filhos, que aumentam a frequência escolar). Esse resultado está alinhado com o estudo de Teixeira (2010), para quem os valores do benefício não são suficientemente grandes para gerar um efeito renda capaz de anular o efeito substituição.

A propensão dos beneficiários em transferir suas atividades para o setor informal foi analisada por Barbosa e Corseuil (2014). Também utilizaram os dados da PNAD, mas, diferentemente dos trabalhos anteriores, que utilizaram a metodologia de propensity score matching, esses autores usaram regressão descontínua e concluíram que o programa não tem impactos sobre a escolha ocupacional dos beneficiários entre postos formais e informais.

Entretanto, De Brauw e colaboradores (2015) encontram resultado distinto, sustentando que, embora não haja efeito no número total de horas de trabalho no domicílio, o programa causa uma realocação "substancial" do número de horas de trabalho do setor formal para o informal. Eles argumentam que a mudança é possivelmente induzida pelo uso dos registros de renda do mercado formal em auditorias com a finalidade de verificar o cumprimento do critério de elegibilidade. Soares e Ribas (2011) encontram redução da participação no mercado formal de beneficiários de grandes cidades e relatam diminuição do número de horas trabalhadas dos beneficiários em áreas mais pobres, embora o benefício tenda a encorajar a participação adicional no mercado formal de trabalho de outros membros do domicílio.

Quanto aos efeitos dos programas de transferência de renda de outros países da América Latina sobre a oferta de trabalho, os resultados empíricos são, grosso modo, semelhantes aos verificados no Brasil. O trabalho de Skoufias e Di Maro (2008) sobre o Progresa do México conclui que de maneira geral o programa não apresenta efeitos significativos sobre a taxa de participação de beneficiários no mercado de trabalho. As exceções ocorrem em grupos específicos: homens com idade entre 35 e 54 anos tiveram aumento estatisticamente significativo na participação, embora de pequena magnitude, e mulheres com idade entre 45 e 54 apresentaram redução na participação no início do programa. Por outro lado, também não se pode afirmar que os beneficiários aloquem mais tempo em atividades de lazer. Parker e Skoufias (2000) apresentam resultados equivalentes.

O trabalho, mais recente, de Alzúa e colaboradores (2013) envolvendo os programas de renda condicionados de México, Nicarágua e Honduras reporta que resultados comparáveis dos três países indicam que os efeitos que os programas tiveram na participação no mercado de trabalho foram, em geral, negativos, mas pequenos e não estatisticamente significantes. Os resultados de Gonzalez-Ro- 
zada e Pinto (2011) e Barrientos e Villa (2013), para Equador e Colômbia, respectivamente, indicam aumento na participação no primeiro caso, e efeito nulo no segundo.

Finalmente, Cepal (2014), num survey abarcando estudos disponíveis para países variados como Argentina, Brasil, Chile, Honduras, México, Nicarágua e Paraguai, não encontra evidências empíricas da existência de desincentivos criados pelos programas à inclusão laboral de beneficiários.

\subsection{DURAÇÃO DO EMPREGO}

A partir do ano 2000, o mercado de trabalho brasileiro foi marcado pelo aumento da criação líquida de empregos formais, de acordo com dados do Cadastro Geral de Empregados e Desempregados (Caged). Conforme ilustra o gráfico 1, no biênio 1998-99, houve mais desligamentos do que admissões de trabalhadores formais na economia brasileira, com 389 mil pessoas perdendo o emprego. Todavia, nos anos 2000, a criação líquida de empregos foi positiva em todos os anos e melhorou substancialmente nos anos recentes. No ano 2000, foram criados 658 mil novos postos de trabalho formal no Brasil, enquanto em 2008 foram criados quase 1,5 milhão e em 2011 foram criados quase 1,6 milhão.

\section{GRÁFICO 1 EVOLUÇÃO DA CRIAÇÃO LÍQUIDA DE POSTOS FORMAIS DE TRABALHO (1998-2011)}

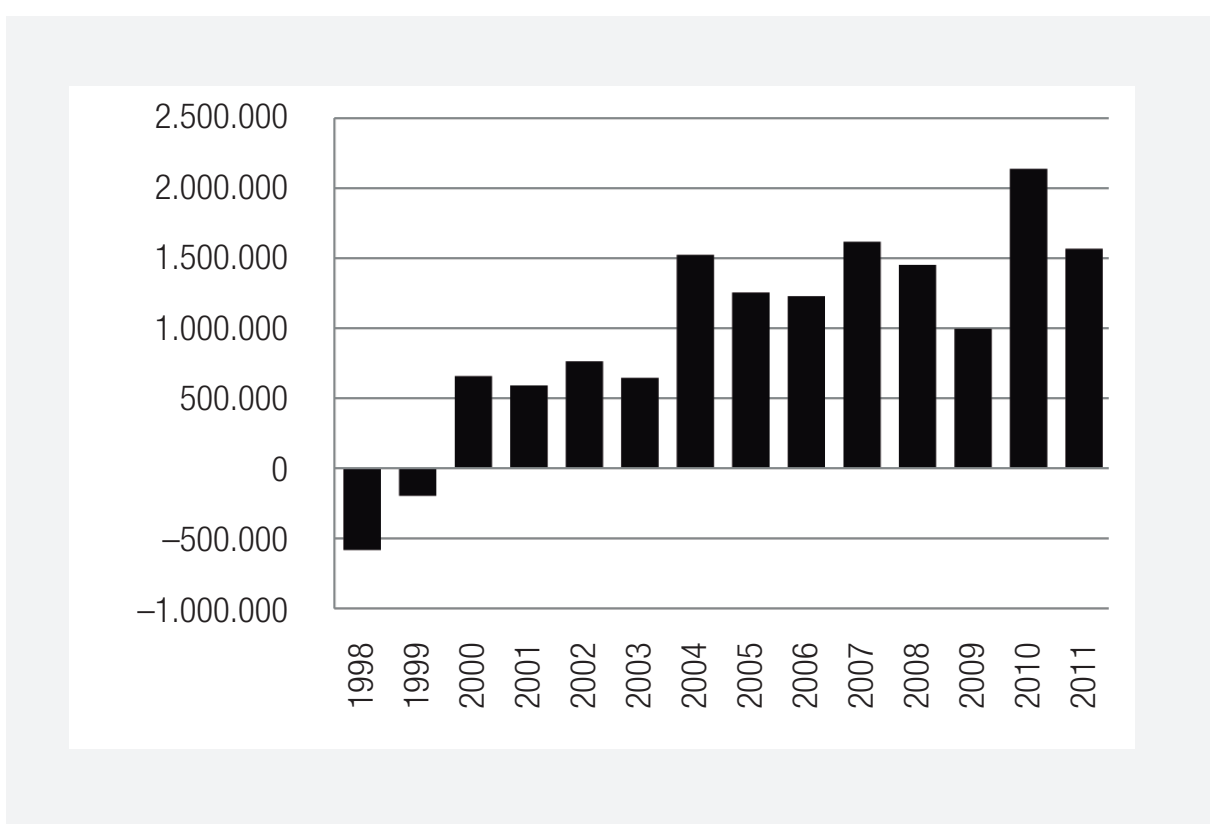

Fonte: Elaborado pelos autores com base em dados do Ministério do Trabalho e Emprego - Cadastro Geral de Empregados e Desempregados (Caged).

Assim como apontado por Menezes-Filho e Picchetti (2000) com relação ao tempo de desemprego, um aspecto tão importante (e menos estudado) quanto a incidência do emprego é sua duração. Ou seja, o tempo que os trabalhadores permanecem no emprego, e como essa duração depende das características dos trabalhadores. A (curta) duração do emprego afeta a aposentadoria do trabalhador de baixa renda, uma vez que encontra maiores dificuldades para comprovar e requerer o benefício 
por tempo de serviço, devido a constantes mudanças de emprego e períodos no desemprego ou no mercado informal (Além et al., 1998).

Como as aposentadorias por tempo de serviço são concedidas, em geral, às pessoas que provêm de empregos estáveis, ou que mudaram pouco de emprego durante a vida profissional (Além et al., 1998), pode-se dizer que a duração do emprego formal é uma medida de qualidade do emprego que impactará o bem-estar futuro do trabalhador.

A esse respeito, Giambiagi e Afonso (2009) enfatizam o quanto a aposentadoria por idade no Brasil possui valor médio inferior ao da aposentadoria por tempo de contribuição. Os autores observam que em dezembro de 2008 foram emitidas 14.453.455 aposentadorias e que, desse total, 7.500.092 $(51,9 \%)$ foram por idade, $2.835 .391(19,6 \%)$ das aposentadorias foram por invalidez e 4.117 .972 $(28,5 \%)$ por tempo de contribuição. Os valores médios das aposentadorias por invalidez e por idade foram, respectivamente, de $\mathrm{R} \$ 552,01$ e $\mathrm{R} \$ 432,97$, enquanto o valor médio das aposentadorias por tempo de contribuição foi de $\mathrm{R} \$ 1.058,93$.

\section{MÉTODO E DESCRIÇÃO DA BASE DE DADOS}

Os dados utilizados neste trabalho são oriundos de três principais fontes: o Cadastro Único (CadÚnico), a Relação Anual de Informações Sociais (Rais) e das folhas de pagamento do Programa Bolsa Família (PBF).

O CadÚnico é um instrumento do Ministério do Desenvolvimento Social e Combate à Fome (MDS) que identifica e caracteriza as famílias de baixa renda, entendidas como aquelas que têm renda mensal de até meio salário mínimo por pessoa ou renda mensal total de até três salários mínimos. É condição necessária para ser beneficiário de programas sociais do governo federal, como o PBF, constar previamente do CadÚnico.

A Rais, por sua vez, é um instrumento de coleta de dados anual, que compete ao Ministério do Trabalho e Emprego, utilizado na gestão pública do setor do trabalho. São obrigados a entregar a declaração da Rais todos os inscritos no CNPJ, com ou sem empregados, inclusive empresas públicas, empresas individuais, órgãos da administração direta e indireta dos governos federal, estadual ou municipal, fundações e empregadores rurais.

Para a construção da base de dados, foram considerados todos os indivíduos com idade entre 16 e 65 anos, admitidos no emprego durante o ano de 2008, e que faziam parte do Cadastro Único (extração de dezembro de 2011). Quando o indivíduo possuía mais de um vínculo no mercado formal, manteve-se somente o principal (o de maior salário). Esses vínculos empregatícios foram, então, acompanhados por um prazo máximo de quatro anos, utilizando as informações das bases Rais de 2009, 2010 e 2011. Caso o vínculo de trabalho seja rompido, por qualquer motivo que seja, antes de dezembro de 2011, o indivíduo deixa de ser acompanhado. Desse modo, acompanhamos somente um vínculo empregatício por indivíduo e não observamos reentradas no emprego.

Esse cruzamento produziu mais de 3 milhões de observações. Apesar de existirem informações de 2008 a 2011, somente a informação mais recente (da data do término do vínculo de trabalho) foi mantida nos registros. Exceção se faz à presença dos indivíduos no PBF, para os quais foi considerada a informação, mensalmente, sobre o recebimento do benefício por parte da família de que esse indivíduo faz parte. A relevância de se considerar o recebimento do benefício como uma variável que varia no tempo ficará mais clara após discussões apresentadas nas subseções 3.1 e 3.2. 


\subsection{ANÁLISE DESCRITIVA}

Os dados para cada indivíduo referem-se ao ano em que se encerrou o vínculo empregatício, ou a 2011, caso o vínculo tenha sido mantido. Conforme pode ser observado na tabela $1,60 \%$ dos indivíduos são homens, $87 \%$ residem em área urbana, $24 \%$ estão em seu primeiro emprego, $7 \%$ são sindicalizados e $47 \%$ eram beneficiários do PBF em dezembro de 2011. A idade média é 33 anos, e cada trabalhador possui, em média, 1,89 filho, sendo 1,18 a média de filhos menores de 18 anos. Os indivíduos permaneceram, em média, 13 meses empregados e somente 18\% deles mantiveram seu vínculo até dezembro de 2011, os quais são considerados observações censuradas.

\section{TABELA 1 ESTATÍSTICAS DESCRITIVAS DAS VARIÁVEIS QUANTITATIVAS OU DICOTÔMICAS}

\begin{tabular}{lccccc} 
Variável & \multicolumn{1}{c}{$\mathbf{N}$} & Média & Desvio-padrão & Mínimo & Máximo \\
\hline Idade & 3.012 .384 & 33,26 & 9,87 & 16 & 1 \\
Homem & 3.012 .384 & 0,60 & 0,49 & 0 & 311 \\
Renda_percap & 3.012 .384 & 89,88 & 63,42 & 0 & 28 \\
Filhos & 3.012 .384 & 1,89 & 1,41 & 0 & 12 \\
Menores & 3.012 .384 & 1,18 & 1,23 & 0 & 3.934 .232 \\
Salário & 2.988 .028 & 616,78 & $4.249,12$ & 0 & 1 \\
Localidade & 3.007 .901 & 0,87 & 0,33 & 0 & 1 \\
Primeiro_emp & 3.012 .384 & 0,24 & 0,42 & 0 & 1 \\
Sindicalizado & 3.012 .379 & 0,071 & 0,26 & 0 & 1 \\
PBF_2011 & 3.012 .384 & 0,47 & 0,50 & 0 & 48 \\
Tempo_emprego & 3.012 .384 & 12,99 & 13,06 & 0 & 1 \\
Censura & 3.012 .384 & 0,18 & 0,39 & 0 & 1
\end{tabular}

Fonte: Elaborada pelos autores.

Nota: Os dados de cada indivíduo referem-se ao ano em que ocorreu o término do vínculo empregatício ou a 2011 , caso o vínculo tenha sido mantido, Idade em anos; Homem: 1- sim, 0- não; Renda_percap indica a renda mensal familiar per capita, em reais, autodeclarada; Filhos indica o número de filhos; menores o número de filhos menores de 18 anos; salário é a média salarial recebida no ano em que houve a quebra do vínculo ou em 2011, caso o vínculo tenha permanecido, considerando valores corrigidos pelo INPC para dezembro de 2011; Localidade: 1- urbana, 0-rural; Primeiro_emp: 1-primeiro emprego, 0- não; Sindicalizado: 1- sim, 0- não; PBF_2011: 1- beneficiário em dezembro de 2011, 0- não; Tempo_emprego indica os meses no emprego; Censura: 1-continuou empregado em dezembro de 2011, 0- não.

A renda mensal familiar per capita, autodeclarada no CadÚnico, possui média próxima a 90 reais, que está dentro do critério de elegibilidade do programa para o ano de 2011, isto é, abaixo de R\$ 140,00. Os valores dos salários mensais recebidos por indivíduo, informação obtida nas bases Rais, foram corrigidos para dezembro de 2011 pelo INPC. A média salarial foi calculada para o ano em que houve a quebra do vínculo de trabalho ou, caso o vínculo tenha sido mantido, para o ano de 2011. A média e o desvio-padrão encontrados para todos os 3 milhões de indivíduos foram, respectivamente, 
$\mathrm{R} \$ 616,78$ e R \$4.249,12. O maior salário observado, próximo a 4 milhões de reais, sugere uma atenção à presença de outliers nessa variável, discussão que será realizada mais à frente, nesta mesma seção. A tabela 2 apresenta as estatísticas descritivas para as variáveis categóricas policotômicas. Nota-se que $45 \%$ dos empregos estão na região Sudeste, seguidos por 23\% no Nordeste, $18 \%$ na região Sul, 8,3\% no Centro-Oeste e 5,7\% na região Norte do país.

\section{TABELA 2 ESTATÍSTICAS DESCRITIVAS DAS VARIÁVEIS POLICOTÔMICAS}

\begin{tabular}{|c|c|c|c|c|}
\hline Variável & $\mathrm{N}$ & Categoria & Média & Desvio-padrão \\
\hline \multirow[t]{5}{*}{ Raça } & 2.843 .787 & Branca & 0,39 & 0,49 \\
\hline & & Amarela & 0,0027 & 0,052 \\
\hline & & Indígena & 0,0034 & 0,058 \\
\hline & & Parda & 0,51 & 0,50 \\
\hline & & Preta & 0,10 & 0,29 \\
\hline \multirow[t]{6}{*}{ Instrução } & 2.313.213 & Sem instrução & 0,072 & 0,26 \\
\hline & & Fundamental incompleto & 0,58 & 0,49 \\
\hline & & Fundamental completo & 0,14 & 0,35 \\
\hline & & Médio incompleto & 0,14 & 0,35 \\
\hline & & Médio completo & 0,055 & 0,23 \\
\hline & & Superior incompleto ou mais & 0,0089 & 0,094 \\
\hline \multirow[t]{5}{*}{ Região } & 3.012 .384 & Nordeste & 0,23 & 0,42 \\
\hline & & Norte & 0,057 & 0,23 \\
\hline & & Centro-Oeste & 0,083 & 0,28 \\
\hline & & Sudeste & 0,45 & 0,50 \\
\hline & & Sul & 0,18 & 0,39 \\
\hline \multirow[t]{4}{*}{ Porte_cidade } & 3.012 .384 & $(0,10 \mathrm{mil}]$ & 0,089 & 0,29 \\
\hline & & (10 mil, 100 mil] & 0,42 & 0,49 \\
\hline & & (100 mil, 1 milhão] & 0,34 & 0,47 \\
\hline & & (1 milhão, +] & 0,15 & 0,36 \\
\hline \multirow[t]{5}{*}{ Porte_estabelecimento } & 3.012 .384 & $(0,10]$ & 0,16 & 0,37 \\
\hline & & $(10,100]$ & 0,35 & 0,48 \\
\hline & & $(100,1.000]$ & 0,29 & 0,46 \\
\hline & & $(1.000,10.000]$ & 0,17 & 0,38 \\
\hline & & $(10.000,+]$ & 0,018 & 0,13 \\
\hline
\end{tabular}


RAP | Os efeitos do Programa Bolsa Família sobre a duração do emprego formal dos indivíduos de baixa renda

\begin{tabular}{|c|c|c|c|c|}
\hline Variável & $\mathrm{N}$ & Categoria & Média & Desvio-padrão \\
\hline \multirow[t]{8}{*}{ CBO } & 3.012 .384 & Agropecuária e pesca & 0,16 & 0,36 \\
\hline & & Indústria — generalistas & 0,33 & 0,47 \\
\hline & & Indústria — operadores & 0,051 & 0,22 \\
\hline & & Manutenção e reparação & 0,023 & 0,15 \\
\hline & & Serviço, comércio & 0,28 & 0,45 \\
\hline & & Serviços administrativos & 0,11 & 0,32 \\
\hline & & Técnicos nível médio & 0,030 & 0,17 \\
\hline & & Outros & 0,020 & 0,14 \\
\hline \multirow[t]{7}{*}{ CNAE } & 3.012 .250 & Administração pública & 0,037 & 0,19 \\
\hline & & Agricultura, pecuária & 0,14 & 0,34 \\
\hline & & Atividades administrativas & 0,10 & 0,31 \\
\hline & & Comércio e repar. veículos & 0,21 & 0,41 \\
\hline & & Contração & 0,13 & 0,33 \\
\hline & & Indústria & 0,20 & 0,40 \\
\hline & & Outros & 0,18 & 0,38 \\
\hline \multirow[t]{9}{*}{ Causa_desligamento } & 2.465 .298 & Aposentadoria & 0,00038 & 0,019 \\
\hline & & Falecimento & 0,0018 & 0,042 \\
\hline & & Res. por j. c. in. empregado & 0,0016 & 0,040 \\
\hline & & Res. por j. c. in. empregador & 0,015 & 0,12 \\
\hline & & Res. sem j. c. in. empregado & 0,18 & 0,39 \\
\hline & & Res. sem j. c. in. empregador & 0,57 & 0,49 \\
\hline & & Transferência & 0,020 & 0,14 \\
\hline & & Término contrato & 0,20 & 0,40 \\
\hline & & Outros & 0,00021 & 0,014 \\
\hline
\end{tabular}

Fonte: Elaborada pelos autores.

Nota: Porte_cidade fornece o número de habitantes na cidade do estabelecimento empregador; Porte_estabelecimento fornece o número de funcionários do estabelecimento empregador; CBO: Classificação Brasileira de Ocupações; CNAE: Classificação Nacional de Atividades Econômicas; Causa_desligamento informa o motivo do término do vínculo empregatício. As abreviaturas Res. por/sem j. c. in. referem-se à rescisão por/sem justa causa iniciativa do.

Uma inspeção inicial comparativa entre os grupos de interesse, os beneficiários e os não beneficiários do PBF é apresentada na tabela 3. É importante notar que os grupos foram discriminados por um apontador de presença no programa em uma data específica e comum para todos os indivíduos, no caso, para dezembro de 2011. Não surpreende que todas as diferenças sejam estatisticamente significativas, dada a grande quantidade de observações em ambos os grupos. 
Vale ressaltar, no entanto, que a magnitude dessas diferenças é bem pequena, com exceção das variáveis que são relacionadas com o critério de concessão do benefício: renda per capita, salário e número de filhos. Como esperado, beneficiários do programa possuem menores salários e mais filhos, tendo, portanto, menor renda familiar per capita. Obviamente, será importante o controle por essas características quando o objetivo for medir o efeito específico do PBF na duração dos vínculos de trabalho, de modo a eliminar a endogeneidade.

\section{TABELA 3 COMPARAÇÃO ENTRE BENEFICIÁRIOS E NÃO BENEFICIÁRIOS DO PROGRAMA BOLSA FAMÍLIA}

\begin{tabular}{|c|c|c|}
\hline Variável & Não beneficiário & Beneficiário \\
\hline Idade & 32,78 & $33,77^{\star \star \star}$ \\
\hline Homem & 0,605 & $0,597^{\star \star \star}$ \\
\hline Renda_percap & 107,30 & $70,32^{\star \star \star}$ \\
\hline Filhos & 1,58 & $2,24^{\star \star \star}$ \\
\hline Menores & 0,77 & $1,64^{\star \star \star}$ \\
\hline Salário & 638,25 & $592,70^{\star \star \star}$ \\
\hline Área_urbana & 0,869 & $0,873^{\star \star \star}$ \\
\hline Primeiro_emp & 0,238 & $0,235^{\star \star \star}$ \\
\hline Sindicalizado & 0,069 & $0,073^{\star \star \star}$ \\
\hline Tempo_emprego & 13,96 & $11,77^{\star \star \star}$ \\
\hline $\mathrm{N}$ & 1.592 .012 & 1.420 .372 \\
\hline
\end{tabular}

Fonte: Elaborada pelos autores.

Nota: Valores médios das variáveis para beneficiários e não beneficiários do PBF em dezembro de 2011. P-value referente ao teste t para diferença de médias: ${ }^{* * *}<0,01$.

Alguma evidência a favor do efeito preguiça é esboçada pelos dois meses a mais no tempo do emprego dos não beneficiários. No entanto, essa análise preliminar carrega um problema merecedor de registro: o fato de o indivíduo ser do PBF em dezembro de 2011 não significa que esse indivíduo era beneficiário no término do vínculo de seu trabalho (veja na tabela 1 que somente $18 \%$ da amostra manteve seus empregos até essa data).

Portanto, a comparação da duração no emprego realizada desse modo não possui validade, uma vez que a alocação dos indivíduos nos grupos não é aleatória, a variável tempo no emprego é censurada (isto é, o emprego só é acompanhado até dezembro de 2011, não se sabe o que ocorre posteriormente) e a participação no programa é analisada num momento fixo no tempo. Assim, para uma correta especificação, o modelo deverá contornar esses três empecilhos.

Na tabela 4 observa-se que $42,5 \%$ dos indivíduos pesquisados mantiveram-se no programa desde o momento em que entraram. Também percebe-se que próximo de um terço dos indivíduos já foi do programa em algum momento, mas após sua saída não mais retornaram a obter o benefício. Somente 
$6,78 \%$ da amostra é composta de indivíduos que voltaram a receber o benefício, após ter deixado o programa em algum momento.

\section{TABELA 4 DINÂMICA DE ENTRADA E SAÍDA NO PBF}

\begin{tabular}{lc} 
Entrou e nunca mais saiu & $42,53 \%$ \\
Saiu e nunca mais voltou & $33,06 \%$ \\
Nunca foi PBF & $17,64 \%$ \\
Saiu e depois voltou & $6,78 \%$ \\
\hline
\end{tabular}

Fonte: Elaborada pelos autores.

Outra questão relevante para avaliar o impacto do $\mathrm{PBF}$ diz respeito aos indivíduos contemplados pelo benefício. Em que pesem as normas de concessão serem baseadas na renda familiar per capita, e no fato de haver gestantes ou menores na composição familiar, isso não é suficiente para garantir a manutenção, tampouco a entrada da família no programa. Mesmo elegível de acordo com os critérios do PBF, é necessário que a família pertença ao CadÚnico, e que possua cadastro atualizado, para que venha a ser contemplada.

A tabela 5 corrobora essa análise ao mostrar que, entre os indivíduos que satisfazem o critério de seleção do PBF em dezembro de 2011, 43\% não recebem o benefício. Os motivos para isso podem ser diversos: o recebimento não é imediato a partir do cadastramento; os dados no CadÚnico podem estar desatualizados; a família pode ter sido desligada em algum processo de auditoria, ou por não ter cumprido alguma das condicionalidades do programa ou por declarar renda incompatível.

\section{TABELA 5 CONTEMPLADOS E ELEGÍVEIS}

\begin{tabular}{l|c|c|c}
\hline \multirow{2}{*}{ Critério PBF } & \multicolumn{2}{c}{ PBF em $12 / 2011$} & Total \\
\hline Satisfaz & Não & Sim & \\
& 972.875 & 1.294 .108 & 2.266 .983 \\
Não satisfaz & $43 \%$ & $57 \%$ & $100 \%$ \\
& 619.137 & 126.264 & 745.401 \\
Total & $83 \%$ & $17 \%$ & $100 \%$ \\
& 1.592 .012 & 1.420 .372 & 3.012 .384 \\
& $53 \%$ & $47 \%$ & $100 \%$ \\
\hline
\end{tabular}

Fonte: Elaborada pelos autores.

Nota: Foram considerados como 'Satisfaz' o critério PBF aqueles com renda per capita abaixo de R\$ 70,00 , ou aqueles com renda per capita abaixo de $\mathrm{R} \$ 140,00$ e que possuíssem ao menos um filho menor de idade na composição familiar. 
Deve-se considerar, também, o fato de a renda familiar per capita ser autodeclarada, de modo que possa haver fraude e famílias fora do escopo definido sejam contempladas. O MDS procura minimizar a incidência desses casos com auditorias periódicas, em que os salários reportados na base Rais são usados para atestar a fidedignidade dos valores reportados. No entanto, existe uma defasagem considerável nesse processo, pois a base Rais é disponibilizada dois anos mais tarde. Além disso, devido ao alto grau de informalidade da economia brasileira, muitos indivíduos que se inserem nesse contexto omitem a parcela não auditável de sua renda para conseguir o benefício (Soares et al., 2010).

O salário informado na base Rais, no entanto, não é reportado pelo indivíduo, mas sim pelo estabelecimento empregador. Dos 3 milhões de indivíduos na amostra, somente 97 casos registram um salário acima de 10 mil reais, entre os quais temos 17 casos acima de 50 mil reais e apenas nove casos com salário superior a 100 mil reais. Existem três possibilidades para essas observações constarem da base: i) erro de registro, o que é bastante provável no caso de um salário de 4 milhões de reais; ii) fraude, uma vez que a renda no CadÚnico é autorreportada; ou iii) indivíduos que prosperaram, já que a base do CadÚnico não elimina os indivíduos que uma vez pertenceram à base.

Salários baixos também são observados. Em torno de 790 mil registros apresentaram salários abaixo de 450 reais, que é menor do que o salário mínimo nacional corrigido pelo INPC em qualquer um dos anos considerados, conforme mostra a tabela 6 . Esses podem estar relacionados com erros de registro, afastamentos temporários ou jornadas de trabalho reduzidas. A Medida Provisória no 2.164-41, de 24 de agosto de 2001, dispôs sobre o regime de trabalho em tempo parcial. À Consolidação das Leis do Trabalho (CLT) foi incorporado o artigo 58-A, que considera trabalho em regime de tempo parcial aquele cuja duração não exceda 25 horas semanais, e cujo parágrafo primeiro estabelece: "o salário a ser pago aos empregados sob o regime de tempo parcial será proporcional à sua jornada, em relação aos empregados que cumprem, nas mesmas funções, tempo integral”.

\section{TABELA 6 SALÁRIO MÍNIMO BRASILEIRO (R\$ CORRIGIDO PELO INPC)}

\begin{tabular}{lcc}
\hline Ano & 10 jan. & dez. 2011 \\
\hline 2008 & 380 & 476 \\
2009 & 415 & 488 \\
2010 & 510 & 576 \\
2011 & 510 & 541 \\
\hline
\end{tabular}

Fonte: Elaborada pelos autores.

Para tratar tanto dos altos quanto dos baixos salários na base de dados, os valores foram separados em 10 classes de salários (tabela 7). No filtro principal usado nas estimações que são apresentadas na seção 4, utilizamos os registros que contêm os $40 \%$ dos salários centrais, as classes de 4 a 7 na tabela 7 . 


\section{TABELA 7 SEPARAÇÃO EM 10 CLASSES DE SALÁRIOS}

\begin{tabular}{|c|c|c|c|}
\hline Classe & Média & Classe & Média \\
\hline 1 & 202,19 & 6 & 587,32 \\
\hline 2 & 373,30 & 7 & 649,56 \\
\hline 3 & 450,58 & 8 & 734,37 \\
\hline 4 & 497,40 & 9 & 868,46 \\
\hline 5 & 539,92 & 10 & $1.390,35$ \\
\hline
\end{tabular}

Fonte: Elaborada pelos autores.

Vale notar que esse filtro, além de considerar na análise salários mais homogêneos, desconsidera salários altos e aqueles inferiores ao salário mínimo.

\subsection{ANÁLISE DE SOBREVIVÊNCIA}

A análise de sobrevivência é um conjunto de procedimentos estatísticos para a análise de dados em que a variável de interesse é o tempo até a ocorrência de determinado evento. Na nomenclatura da sobrevivência, quando o evento ocorre, diz-se que foi observada a "falha". E, caso contrário, se o evento de interesse não ocorrer durante o universo de tempo da análise, diz-se que a informação é "censurada". Para esse estudo, a variável analisada é o tempo no emprego e o evento de interesse, o desligamento (saída) do emprego. Os tempos de emprego de todos aqueles que permaneceram empregados até dezembro de 2011 são censurados.

Considerando uma variável aleatória $t$, com densidade de probabilidade $f(t)$ e distribuição acumulada $F(t)$, define-se $a$, função de sobrevivência por

$$
S(t)=1-F(t)=P(T>t)
$$

e a função de risco por

$$
h(t)=\lim _{\Delta t \rightarrow 0} \frac{P(t \leq T<t+\Delta t \mid T \geq t)}{\Delta t}=\frac{f(t)}{1-F(t)}=\frac{f(t)}{S(t)}
$$

Enquanto a função de sobrevivência indica a probabilidade de permanecer no emprego mais que um tempo específico, a função risco é uma taxa que representa o potencial de o emprego terminar num dado instante, dado que ele durou até aquela data.

A função de sobrevivência pode ser estimada usando o método de Kaplan-Meier. Esse estimador ordena os tempos de falhas e calcula a probabilidade de sobrevida em cada intervalo de tempo, levando-se em consideração somente os indivíduos em risco. Desse modo, a questão da "censura" é considerada por esse estimador. Esse é um procedimento não paramétrico, uma vez que não impõe nenhum modelo teórico para as falhas (ou censuras) observadas na amostra. No 
entanto, esse método não permite estimar os efeitos conjuntos de um grupo de covariadas sobre a duração do emprego. Para tanto, são necessários outros métodos que incorporem as variáveis explicativas no modelo.

O mais comum desses métodos é o chamado modelo de riscos proporcionais de Cox. A forma da função de risco é

$$
h(t, \boldsymbol{X})=h_{0}(t) e^{\sum_{i=1}^{p} \beta i X i},
$$

onde $\boldsymbol{X}=\left(X_{1}, X_{2}, \ldots, X_{p}\right)$ é o vetor de variáveis explicativas e $h_{0}(t)$ é a chamada função de risco base, comum a todos os indivíduos. Assim, esse modelo considera que as características individuais determinam o risco de cada elemento da amostra como um múltiplo do risco comum a todos os indivíduos. Por não especificar a função $h_{0}(t)$, essa metodologia é chamada de semiparamétrica. Em contraste, os modelos paramétricos são aqueles em que a forma funcional da $h_{0}(t)$ está completamente especificada, exceto os valores dos parâmetros desconhecidos. Por exemplo, a função de risco de Weibull é dada por $h(t, X)=\lambda p t^{p-1}$, onde $h_{0}(t)=p t^{p-1}$ e $\lambda=e^{\sum_{i=1}^{p} \beta i X i}$.

Uma das principais razões para a popularidade do modelo de Cox é que, apesar da função de risco base não ser especificada, boas estimativas dos coeficientes de regressão são obtidas. Isto é, o modelo é robusto no sentido de que os resultados do modelo de Cox aproximam-se dos resultados do modelo paramétrico corretamente especificado (Kleinbaum e Klein, 2006). Deve-se atentar que função de risco envolve o produto de duas funções, o risco base $\left(h_{0}(t)\right)$, que é uma função de $t$ mas não de $\boldsymbol{X}$, e a exponencial ( $\left.e^{\Sigma_{i=1}^{p} \beta i X i}\right)$, que é uma função de $\boldsymbol{X}$ mas não de $t$. Por isso as características $\boldsymbol{X}$ são chamadas de invariantes no tempo.

A função de risco considerando covariadas que variam no tempo pode ser expressa por

$$
h(t, \boldsymbol{X}(t))=\lim _{\Delta t \rightarrow 0} \frac{P(t \leq T<t+\Delta t \mid T \geq t, \boldsymbol{X}(t+\Delta t))}{\Delta t}
$$

Uma discussão detalhada sobre a existência desse limite pode ser encontrada em Lancaster (1992). Mas, segundo Wooldridge (2010), uma condição suficiente ocorre quando $\boldsymbol{X}(t)$ assume valores constantes em intervalos de tempo, como dias, semanas ou meses. Neste estudo, a variável $p b f$ assume valores 1 (para beneficiários) ou 0 (para não beneficiários), em intervalos de tempo de no mínimo um mês (período entre folhas de pagamento).

O modelo de Cox pode ser estendido para covariáveis variando no tempo:

$$
h(t, \boldsymbol{X}(t))=h_{0}(t) e^{\sum_{i=1}^{p} \beta i X i(t)} .
$$

Segundo Kleinbaum e Klein (2006), um pressuposto importante do modelo de Cox estendido é que o efeito de uma variável variante no tempo sobre a probabilidade de sobrevivência no tempo $t$ deve depender do valor dessa variável no mesmo instante de tempo, e não do seu valor passado ou futuro. Parece razoável que a decisão de deixar ou não o emprego em cada instante seja influenciada pelo fato de o indivíduo ser beneficiário do PBF nesse momento, e não por já ter sido beneficiário no passado ou pela expectativa futura de vir a ser. 


\section{RESULTADOS}

No gráfico 2 estão apresentadas as funções de sobrevivência e risco estimadas pelo modelo não paramétrico de Kaplan-Meier. A durabilidade média do emprego foi de 597 dias (20 meses) com mediana de 424 dias (14 meses), o que indica que metade dos indivíduos perde ou deixa seus empregos em menos de um ano e dois meses de trabalho.

\section{GRÁFICO 2 CURVAS DE KAPLAN-MEIER}

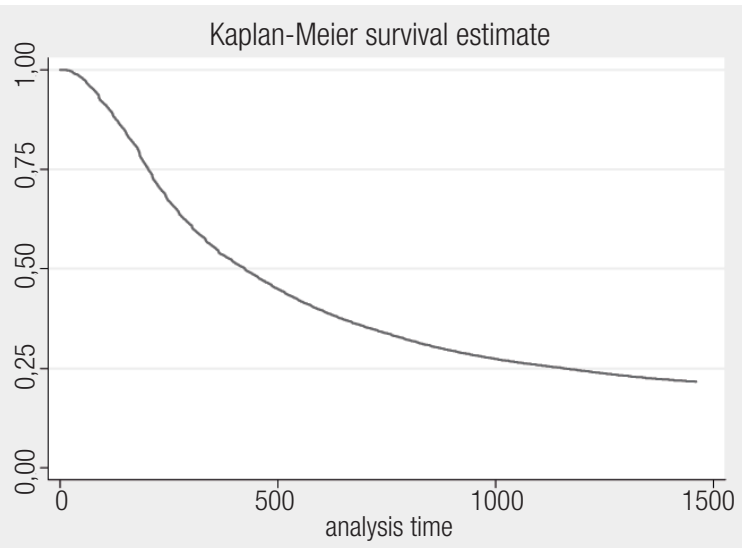

(a) Função de sobrevivência

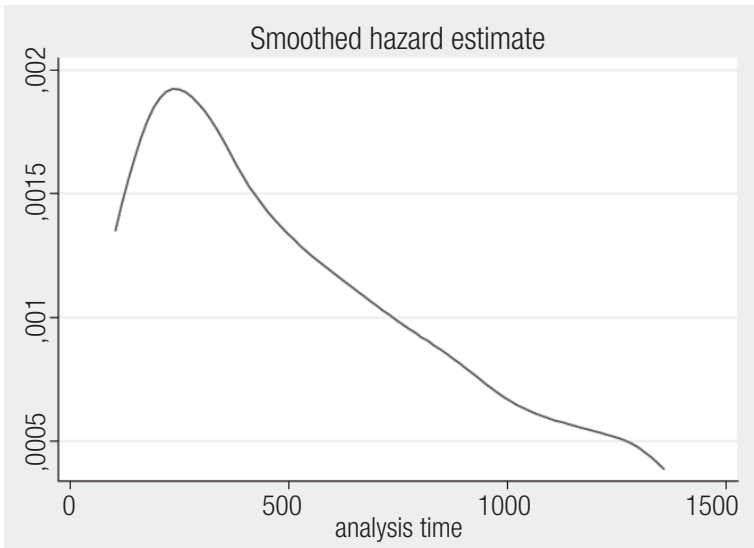

(b) Função risco

Fonte: Elaborado pelos autores.

O gráfico 3 mostra as funções de sobrevivência e risco para os beneficiários ( $p b f=1$ ) e não beneficiários $(p b f=0)$ do PBF. Nota-se que a sobrevida para os beneficiários é maior do que para os não beneficiários. Vale lembrar que essa variável que indica a presença no PBF é variável no tempo.

\section{GRÁFICO 3 CURVAS DE KAPLAN-MEIER PARA BENEFICIÁRIOS E NÃO BENEFICIÁRIOS DO PBF}

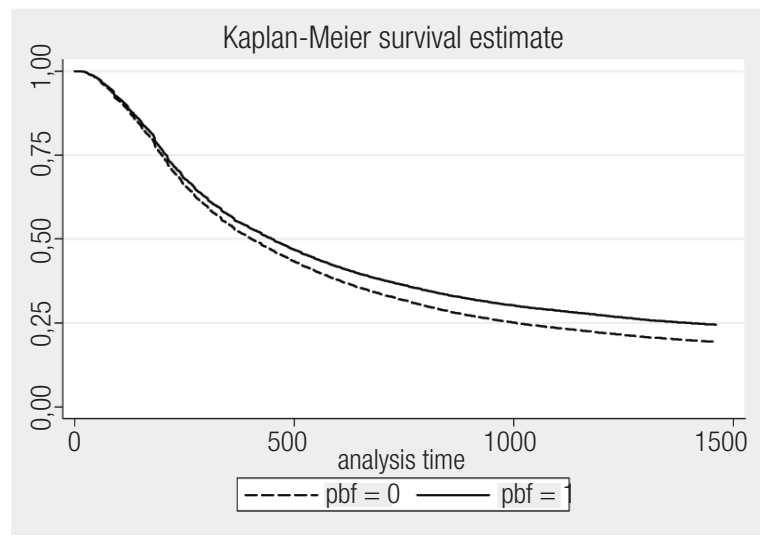

(a) Função de sobrevivência

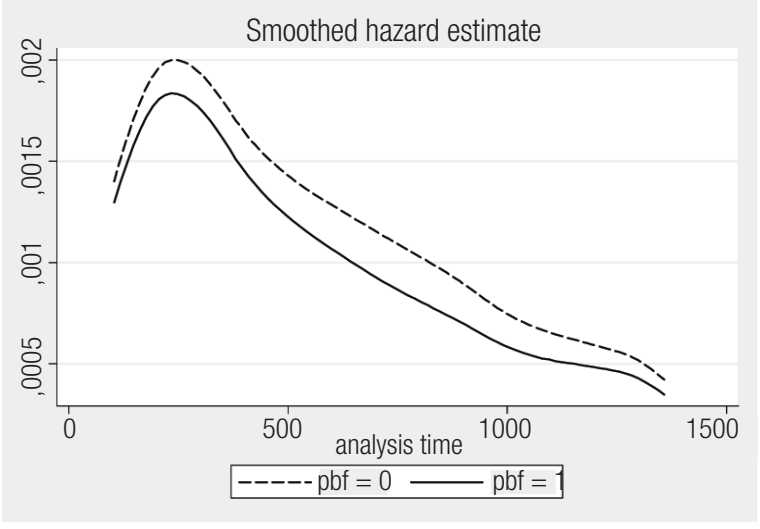

(b) Função risco

Fonte: Elaborado pelos autores. 
Nessa inspeção inicial, que diz respeito às curvas de Kaplan-Meier, a amostra utilizada foi de todos os admitidos em 2008 que se mantiveram no emprego até o final de 2011 ou que quebraram o vínculo de trabalho pelo motivo de rescisão (tanto por justa causa quanto sem justa causa e tanto por iniciativa do empregado quanto por iniciativa do empregador) e que possuíam remuneração entre as classes de salários de 4 a 7, conforme a tabela 7. Assim, a amostra contou com 1.007.315 indivíduos, dos quais 771.634 apresentaram a falha (saíram do emprego). O restante, 235.681 indivíduos, permaneceu até dezembro de 2011 no emprego (dados censurados).

Utiliza-se o modelo de Cox para quantificar o efeito na duração do emprego da covariável tempo-dependente de presença no $\mathrm{PBF}$, controlando pelos outros fatores, os quais são invariantes no tempo. De acordo com a discussão feita na seção 3.2, esse constitui o principal resultado deste artigo. Essa especificação é capaz de tratar dos problemas elencados na seção 3.1, pois os modelos de sobrevivência consideram a questão da censura, a dinâmica de entrada e saída no PBF é contemplada e as diferenças entre os grupos são controladas por diversas características individuais. O tamanho amostral permite a inclusão de inúmeros controles, o que favorece nossa hipótese de identificação: que o controle por características observáveis é suficiente para eliminar a endogeneidade.

A tabela 8 apresenta as razões de risco estimadas para cinco modelos em que o recorte amostral foi sendo alterado. A ideia de alterar a amostra permite acrescentar robustez aos resultados, à medida que as estimativas convergem.

\section{TABELA 8 RAZÕES DE RISCO DAS REGRESSÕES DE COX PARA 0 TEMPO NO EMPREGO}

\begin{tabular}{|c|c|c|c|c|c|}
\hline & (1) & (2) & (3) & (4) & (5) \\
\hline PBF & $0,923^{\star \star \star}$ & $0,929^{\star \star \star}$ & $0,898^{\star \star \star}$ & $0,904^{\star \star \star}$ & $0,913^{\star \star \star}$ \\
\hline Idade & $0,991^{* * *}$ & $0,993^{* * *}$ & $0,995^{\star \star \star}$ & $0,996^{\star \star *}$ & $0,996^{\star \star \star}$ \\
\hline Homem & $1,234^{\star \star \star}$ & $1,214^{\star \star \star}$ & $1,214^{\star \star \star}$ & $1,196^{\star \star \star}$ & $1,027^{\star \star \star}$ \\
\hline Salário & $0,997^{\star \star \star}$ & $0,997^{\star \star \star}$ & $0,997^{\star \star \star}$ & $0,997^{\star \star \star}$ & $0,999^{\star \star \star}$ \\
\hline Renda_percap & $0,999^{\star \star *}$ & $0,999^{\star \star \star}$ & $0,999^{\star \star \star}$ & $0,999^{\star \star \star}$ & $0,999^{\star \star *}$ \\
\hline Filhos & $0,976^{\star \star \star}$ & $0,976^{\star \star \star}$ & $0,981^{\star \star \star}$ & $0,979^{\star \star \star}$ & $0,985^{\star \star \star}$ \\
\hline Menores & $1,033^{\star \star \star}$ & $1,035^{\star \star \star}$ & $1,031^{\star \star \star}$ & $1,032^{\star \star \star}$ & $1,022^{\star \star \star}$ \\
\hline Primeiro_emp & $0,902^{\star \star \star}$ & $0,928^{\star \star \star}$ & $0,897^{\star \star \star}$ & $0,908^{\star \star *}$ & $0,926^{\star \star \star}$ \\
\hline Sindicalizado & $0,918^{\star \star \star}$ & $0,863^{\star \star \star}$ & $0,960^{\star \star \star}$ & $0,916^{\star \star *}$ & $0,891^{\star \star *}$ \\
\hline Localidade & $1,097^{\star \star \star}$ & $1,096^{\star \star \star}$ & $1,096^{\star \star \star}$ & $1,092^{\star * *}$ & $1,095^{\star \star \star}$ \\
\hline \multicolumn{6}{|c|}{ Raça (ref.: Preta) } \\
\hline Amarela & $1,142^{*}$ & $1,133^{\star \star}$ & 0,994 & 1,018 & 1,018 \\
\hline Branca & $1,087^{\star \star \star}$ & $1,092^{\star \star \star}$ & $1,076^{\star \star \star}$ & $1,074^{\star \star \star}$ & $1,037^{\star \star \star}$ \\
\hline Indígena & 1,059 & $1,256^{\star \star \star}$ & $1,146^{\star \star \star}$ & $1,210^{\star \star \star}$ & $1,265^{\star \star \star}$ \\
\hline Parda & 1,018 & $1,042^{\star \star \star}$ & $1,027^{\star \star \star}$ & $1,029^{\star \star \star}$ & $1,012^{\star \star \star}$ \\
\hline
\end{tabular}


RAP | Os efeitos do Programa Bolsa Família sobre a duração do emprego formal dos indivíduos de baixa renda

\begin{tabular}{|c|c|c|c|c|c|}
\hline & (1) & (2) & (3) & (4) & (5) \\
\hline \multicolumn{6}{|c|}{ Instrução (ref.: Superior inc. ou mais) } \\
\hline Sem instrução & $0,871^{\star \star \star}$ & $0,842^{\star \star \star}$ & $0,885^{\star \star \star}$ & $0,890^{\star \star \star}$ & $0,917^{\star \star \star}$ \\
\hline Fundamental incompleto & $0,875^{\star \star \star}$ & $0,852^{\star \star \star}$ & $0,906^{\star \star \star}$ & $0,908^{\star \star \star}$ & $0,915^{\star \star \star}$ \\
\hline Fundamental completo & $0,890^{\star *}$ & $0,850^{\star \star \star}$ & $0,918^{\star \star \star}$ & $0,912^{\star \star \star}$ & $0,913^{\star \star \star}$ \\
\hline Médio incompleto & $0,896^{\star \star}$ & $0,866^{\star \star \star}$ & $0,917^{\star \star \star}$ & $0,904^{\star \star \star}$ & $0,896^{\star \star \star}$ \\
\hline Médio completo & $0,881^{* *}$ & $0,850^{\star \star \star}$ & $0,911^{\star \star \star}$ & $0,907^{\star \star \star}$ & $0,910^{\star \star \star}$ \\
\hline \multicolumn{6}{|l|}{ Região (ref.: Sul) } \\
\hline Centro-Oeste & $0,840^{\star \star \star}$ & $0,976^{\star}$ & $0,863^{\star \star \star}$ & $0,975^{\star \star \star}$ & $0,968^{\star \star \star}$ \\
\hline Nordeste & $0,460^{\star \star \star}$ & $0,592^{\star \star \star}$ & $0,517^{\star \star \star}$ & $0,638^{\star \star \star}$ & $0,736^{\star \star \star}$ \\
\hline Norte & $0,612^{\star \star \star}$ & $0,745^{\star \star \star}$ & $0,707^{\star \star \star}$ & $0,833^{\star \star \star}$ & $0,866^{\star \star *}$ \\
\hline Sudeste & $0,826^{\star \star \star}$ & $0,944^{\star \star \star}$ & $0,860^{\star \star \star}$ & $0,975^{\star \star \star}$ & $1,016^{\star \star \star}$ \\
\hline \multicolumn{6}{|l|}{ Porte_cidade (ref.: (0, 10 mil]) } \\
\hline (10 mil, $100 \mathrm{mil}]$ & 1,011 & 1,006 & $1,032^{\star \star \star}$ & $1,023^{\star \star \star}$ & $1,057^{\star \star \star}$ \\
\hline (100 mil, 1 milhão] & $1,097^{\star \star \star}$ & $1044^{* \star *}$ & $1,078^{\star \star \star}$ & $1,037^{\star \star \star}$ & $1,066^{\star \star *}$ \\
\hline (1 milhão, +] & 1,023 & 0,992 & $1,066^{\star \star \star}$ & $1,024^{\star \star \star}$ & $1,026^{\star \star \star}$ \\
\hline \multicolumn{6}{|c|}{ Porte_estabelecimento (ref.: $[0,10])$} \\
\hline$[10,100]$ & $1,308^{\star \star \star}$ & $1,260^{\star \star \star}$ & $1,267^{\star \star \star}$ & $1,231^{\star \star \star}$ & $1,333^{\star \star \star}$ \\
\hline$[100,1.000]$ & $1,386^{\star \star \star}$ & $1,295^{\star \star \star}$ & $1,323^{\star \star \star}$ & $1,246^{\star \star \star}$ & $1,390^{\star \star \star}$ \\
\hline$[1.000,10.000]$ & $1,487^{\star \star \star}$ & $1,411^{\star \star \star}$ & $1,412^{\star \star \star}$ & $1,327^{\star \star \star}$ & $1472^{\star \star \star}$ \\
\hline$[10.000,+]$ & $1,238^{\star \star \star}$ & $1,178^{\star \star \star}$ & $1,107^{\star \star \star}$ & $1,112^{\star \star \star}$ & $1,306^{\star \star \star}$ \\
\hline \multicolumn{6}{|l|}{ CBO (ref.: Agropecuária e pesca) } \\
\hline Indústria — generalistas & $0,883^{\star \star \star}$ & $0,901^{\star \star \star}$ & $0,880^{\star \star \star}$ & $0,881^{\star \star \star}$ & $0,804^{\star * \star}$ \\
\hline Indústria — operadores & $0,870^{\star \star \star}$ & $0,821^{\star \star \star}$ & $0,918^{\star \star \star}$ & $0,866^{\star \star \star}$ & $0,786^{\star \star \star}$ \\
\hline Manutenção e reparação & $0,783^{\star \star \star}$ & $0,786^{* \star *}$ & $0,836^{\star \star \star}$ & $0,829^{\star \star \star}$ & $0,737^{\star \star \star}$ \\
\hline Serviço, comércio & $0,749^{\star \star \star}$ & $0,762^{\star \star \star}$ & $0,786^{\star \star \star}$ & $0,765^{\star \star \star}$ & $0,669^{\star \star \star}$ \\
\hline Serviços administrativos & $0,743^{\star \star \star}$ & $0747^{\star \star \star}$ & $0,787^{\star \star \star}$ & $0,751^{\star \star \star}$ & $0,628^{\star \star \star}$ \\
\hline Técnicos nível médio & $0,760^{\star \star \star}$ & $0,764^{\star \star \star}$ & $0,825^{\star \star \star}$ & $0,804^{\star \star \star}$ & $0,710^{\star \star \star}$ \\
\hline Outros & $0,837^{\star \star \star}$ & $0,822^{\star \star \star}$ & $0,837^{\star \star \star}$ & $0,807^{\star \star \star}$ & $0,731^{\star * \star}$ \\
\hline \multicolumn{6}{|c|}{ CNAE (ref.: administração pública) } \\
\hline Agricultura, pecuária & $3,041^{\star \star \star}$ & $3,316^{* \star *}$ & $3,161^{\star \star \star}$ & $3,048^{\star \star \star}$ & $1,994^{\star \star \star}$ \\
\hline Atividades administrativas & $2,981^{\star \star \star}$ & $3,083^{* \star *}$ & $2,789^{\star \star \star}$ & $2,656^{\star \star \star}$ & $1,866^{\star \star \star}$ \\
\hline Comércio e repar. veículos & $3,864^{\star \star \star}$ & $3,681^{* * *}$ & $3,585^{\star \star \star}$ & $3,239^{\star \star \star}$ & $1847^{\star \star \star}$ \\
\hline Contração & $5,903^{\star \star \star}$ & $5,638^{\star \star \star}$ & $4,854^{\star \star \star}$ & $4418^{\star \star \star}$ & $2,469^{\star \star \star}$ \\
\hline Indústria & $3,457^{\star \star \star}$ & $3,381^{\star \star \star}$ & $3,385^{\star \star \star}$ & $3,108^{\star \star \star}$ & $1,727^{\star \star \star}$ \\
\hline
\end{tabular}




\begin{tabular}{|c|c|c|c|c|c|}
\hline & (1) & (2) & (3) & (4) & (5) \\
\hline Outros & $3,699^{\star \star \star}$ & $3474^{\star \star \star}$ & $3,466^{\star \star \star}$ & $3,104^{\star \star \star}$ & $1,689^{\star \star \star}$ \\
\hline Admissão & jan/08 & jan/08 & 2008 & 2008 & 2008 \\
\hline Classes de salário & 4 a 7 & 2 a 9 & 4 a 7 & 2 a 9 & 1 a 10 \\
\hline Causa desligamento & rescisão & rescisão & rescisão & rescisão & todas \\
\hline Núm. observações & 85.663 & 168.565 & 909.291 & 1.766 .564 & 2.617 .064 \\
\hline Núm. indivíduos & 69.537 & 138.370 & 729.786 & 1.432 .657 & 2.178 .741 \\
\hline Núm. falhas & 56.386 & 114.933 & 565.040 & 1.136 .191 & 1.805 .839 \\
\hline Wald chi2 (43) & $11.398^{\star \star \star}$ & $24.867^{\star \star \star}$ & $80.857^{\text {*** }}$ & $198.900^{\star \star \star}$ & $146.435^{\star \star \star}$ \\
\hline
\end{tabular}

Fonte: Elaborada pelos autores.

Nota: P-value: ${ }^{*}<0,10,{ }^{* *}<0,05,{ }^{* *}<0,01$

No modelo 1 consideram-se somente os admitidos em janeiro de 2008, com salários pertencentes às classes de 4 a 7 e que saíram do emprego por motivo de rescisão (por ou sem justa causa e iniciativa do empregado ou empregador). A restrição para admitidos em janeiro de 2008 permite analisar um grupo em que todos os indivíduos estão expostos às mesmas condições macroeconômicas desde o início de seus empregos. Concentrar a análise em torno de salários mais homogêneos também ajuda a garantir que os grupos controle e tratamento contenham, de fato, indivíduos comparáveis.

No modelo 2 a restrição de salário foi relaxada para as classes de 2 a 9. Nos modelos 3 e 4 procede-se do mesmo modo, mas considerando todos os admitidos no ano de 2008. Por fim, o modelo 5 considerou toda a amostra sem nenhuma restrição, nem para salários, nem para a causa do desligamento.

Nota-se que o impacto do PBF, medido pela razão de risco, variou de 0,898 a 0,929 de acordo com a amostra utilizada. Mesmo na última regressão, em que todas as restrições foram relaxadas, inclusive quanto às causas do desligamento do emprego, foi encontrado um valor intermediário, 0,913. Esses resultados mostram que beneficiários do PBF possuem chance de $7 \%$ a $10 \%$ menor de sair de seus empregos em comparação com não beneficiários, o que não só contraria a hipótese de um efeito preguiça resultante da transferência de renda como abre margem para a possibilidade de que essa renda extra produza um incentivo para a permanência no emprego.

Esse efeito, de um programa de transferência de renda condicionado, no presente estudo medido sobre a duração do emprego formal, está alinhado com diversos outros estudos que encontraram evidências de aumento na oferta de trabalho para os beneficiários (Brito e Kerstenetzky, 2011; Medeiros et al., 2007; Tavares, 2010; Teixeira, 2010). O argumento é que, conforme os filhos deixam de ficar em casa e passam a frequentar a escola, os pais passam a ter mais tempo disponível para o trabalho.

No entanto, o resultado também pode ser explicado não pelo caminho das condicionalidades do programa, mas pelo benefício em si. Em 2011, o valor médio do benefício por família era de $\mathrm{R} \$ 120,19$. Por menor que pareça o valor desse benefício financeiro, para uma família que vive com menos de 140 reais per capita (ou menos de 70 reais), essa renda extra pode fazer muita diferença, à medida que o dinheiro é usado na atenção com seus dependentes. Corrobora essa análise o estudo de Oliveira e colaboradores (2007), que constatou que o efeito do PBF sobre o consumo das famílias beneficiárias recaiu sobre os gastos com alimentação, educação e roupas das crianças. $\mathrm{O}$ aumento das despesas com vestuário infantil é semelhante aos impactos registrados para os programas de transferência de 
renda no México e Colômbia, e está relacionado com a percepção das famílias de que o benefício é um bônus para ser gasto no melhor interesse de seus filhos (Soares et al., 2010).

Um exercício simples mas interessante é notar (com base na regressão de número 3 na tabela 8) que o risco de deixar o emprego é 3,1\% maior para indivíduos que têm um filho menor de idade (razão de risco: $\mathrm{e}^{0,030529}=1,031$ ). Já um indivíduo com três filhos menores, em comparação com um indivíduo sem filho menor de idade, teria 9,6\% mais chance de deixar seu emprego (razão de risco: $e^{3 \cdot 0,030529}=1,096$ ). Ser beneficiário do PBF é capaz, no entanto, de anular esse efeito (razão de risco: $1,096 \cdot 0,898=0,984)$. Em outras palavras, suponha um empregador que está entre um candidato que não é beneficiário do PBF e não possui filho menor de idade e um outro candidato com três filhos menores de idade. Ceteris paribus, se esse outro candidato com três filhos menores for beneficiário do PBF, ele terá as mesmas chances de permanecer no emprego do que o primeiro.

Com relação às variáveis de controle, pode-se notar um menor risco de saída do emprego para moradores da região Nordeste, moradores de áreas rurais, pessoas com mais idade, mulheres, os que recebem melhores salários, os que estão no primeiro emprego e empregados na administração pública. Também observa-se que aqueles que se declaram de cor preta têm menos chance de deixar seus empregos do que aqueles que se declaram de cor branca. Conforme apontado por Menezes-Filho e colaboradores (2008) e Garcia e Dedecca (2013), a sindicalização se relaciona com a estabilidade dos vínculos empregatícios, a produtividade e os salários. O resultado para a variável sindicalizado indica que empregados com vínculo sindical são menos propensos a sair dos empregos.

Um maior risco de saída do emprego é observado para empregados da construção civil, para moradores da região Sul do país, indivíduos com grau de instrução acima do ensino médio e moradores em cidades grandes, com porte entre 100 mil e 1 milhão de indivíduos. A grande maioria desses resultados está em linha com a literatura sobre duração do emprego ou do desemprego, elaboradas nas diversas regiões do país: Menezes-Filho e Picchetti (2000); Penido e Machado (2002); Malbouisson e Menezes (2004); Menezes e Dedecca (2006); Antigo e Machado (2006); Oliveira e Carvalho Júnior (2009); Leichsenring (2010); Lira (2011).

Adicionalmente, ajustam-se modelos paramétricos cujos coeficientes estimados podem ser vistos na tabela 9. Todos esses modelos estão na forma de aceleração de tempo de falha (AFT). Nesse contexto, um sinal positivo para o coeficiente indica maior chance de sobrevivência (mais tempo no emprego). Ao contrário do modelo de Cox, onde indica a razão de risco, na métrica AFT a quantidade fornece a razão de tempo de sobrevivência. Por exemplo, o coeficiente estimado para a variável $p b f$ no modelo Loglogístico foi de 0,093 . Esse valor representa uma razão de tempo de sobrevivência de beneficiários versus não beneficiários de $\mathrm{e}^{0,093}=1,097$, o que significa que os beneficiários do PBF possuem uma sobrevida no emprego $9,7 \%$ maior do que os não beneficiários.

Segundo os critérios de Akaike (AIC) e Bayesiano (BIC), o melhor ajuste ficou por conta da função Gamma, na qual o coeficiente estimado foi de 0,086 , o efeito mais conservador entre todos os modelos. Esse valor indica que os beneficiários do PBF permanecem no emprego por um tempo 8,95\% maior que os não beneficiários, com intervalo de $95 \%$ de confiança compreendido entre 8,34\% e 9,56\%.

Em virtude das exigências em relação à distribuição dos dados nos modelos paramétricos, o fato de haver estabilidade nas estimativas demonstra robustez nos resultados. Para se ter ideia da convergência nas estimativas, vale frisar que o coeficiente estimado para a variável pbfno modelo exponencial na métrica AFT $(0,117)$ corresponde a uma razão de risco de 0,889. Esse valor está em linha com o resultado obtido no modelo semiparamétrico de Cox (modelo 3 da tabela 8). 


\section{TABELA 9 COEFICIENTES ESTIMADOS NOS MODELOS PARAMÉTRICOS}

\begin{tabular}{|c|c|c|c|c|c|}
\hline & Exponencial & Weibull & Loglogística & Lognormal & Gamma \\
\hline PBF & $0,117^{\star \star \star}$ & $0,114^{\star \star \star}$ & $0,093^{\star \star \star}$ & $0,095^{\star \star \star}$ & $0,086^{\star \star *}$ \\
\hline Idade & $0,006^{\star \star \star}$ & $0,006^{\star \star \star}$ & $0,004^{\star \star \star}$ & $0,004^{\star \star \star}$ & $0,003^{\star \star \star}$ \\
\hline Homem & $-0,202^{\star \star \star}$ & $-0,198^{\star \star \star}$ & $-0,223^{\star \star \star}$ & $-0,216^{\star \star \star}$ & $-0,214^{\star \star \star}$ \\
\hline Salário & $0,004^{\star \star \star}$ & $0,004^{\star \star \star}$ & $0,004^{\star \star \star}$ & $0,004^{\star \star \star}$ & $0,003^{\star \star \star}$ \\
\hline Renda_percap & $0,001^{\star \star \star}$ & $0,001^{\star \star \star}$ & $0,001^{\star \star \star}$ & $0,001^{\star \star \star}$ & $0,001^{\star \star \star}$ \\
\hline Filhos & $0,020^{\star \star \star}$ & $0,020^{\star \star \star}$ & $0,023^{\star \star \star}$ & $0,022^{\star \star \star}$ & $0,022^{\star \star \star}$ \\
\hline Menores & $-0,032^{\star \star \star}$ & $-0,032^{\star \star \star}$ & $-0,031^{\star \star \star}$ & $-0,030^{\star \star \star}$ & $-0,029^{\star \star \star}$ \\
\hline Primeiro_emp & $0,109^{\star \star \star}$ & $0,107^{\star \star \star}$ & $0,126^{\star \star \star}$ & $0,118^{* \star *}$ & $0,115^{\star \star \star}$ \\
\hline Sindicalizado & $0,036^{\star \star \star}$ & $0,036^{\star \star \star}$ & $0,053^{\star \star \star}$ & $0,058^{\star \star \star}$ & $0,070^{\star \star \star}$ \\
\hline Localidade & $-0,094^{\star \star \star}$ & $-0,092^{\star \star \star}$ & $-0,108^{\star \star \star}$ & $-0,100^{\star \star \star}$ & $-0,096^{\star \star \star}$ \\
\hline \multicolumn{6}{|l|}{ Raça (ref.: Preta) } \\
\hline Amarela & 0,007 & 0,007 & 0,002 & 0,005 & 0,006 \\
\hline Branca & $-0,077^{\star \star \star}$ & $-0,076^{\star \star *}$ & $-0,081^{\star \star \star}$ & $-0,079^{\star \star \star}$ & $-0,079^{\star \star \star}$ \\
\hline Indígena & $-0,130^{\star \star \star}$ & $-0,129^{\star \star \star}$ & $-0,132^{\star \star \star}$ & $-0,127^{\star \star \star}$ & $-0,123^{\star \star \star}$ \\
\hline Parda & $-0,028^{\star \star \star}$ & $-0,028^{* \star *}$ & $-0,026^{\star \star \star}$ & $-0,027^{\star \star \star}$ & $-0,027^{\star \star \star}$ \\
\hline \multicolumn{6}{|c|}{ Instrução (ref.: Superior inc. ou mais) } \\
\hline Sem instrução & $0,126^{\star \star \star}$ & $0,123^{\star \star \star}$ & $0,137^{\star \star \star}$ & $0,131^{\star \star \star}$ & $0,130^{\star \star \star}$ \\
\hline Fundamental incompleto & $0,101^{\star \star \star}$ & $0,099^{\star \star \star}$ & $0,124^{\star \star \star}$ & $0,119^{\star \star \star}$ & $0,122^{\star \star \star}$ \\
\hline Fundamental completo & $0,085^{\star \star \star}$ & $0,083^{\star \star \star}$ & $0,115^{\star \star \star}$ & $0,109^{\star \star \star}$ & $0,115^{\star \star \star}$ \\
\hline Médio incompleto & $0,085^{\star \star \star}$ & $0,083^{\star \star \star}$ & $0,119^{\star \star \star}$ & $0,113^{\star \star \star}$ & $0,120^{\star \star *}$ \\
\hline Médio completo & $0,089^{\star \star \star}$ & $0,087^{\star \star \star}$ & $0,135^{\star \star \star}$ & $0,126^{\star \star \star}$ & $0,135^{\star \star \star}$ \\
\hline \multicolumn{6}{|l|}{ Região (ref.: Sul) } \\
\hline Centro-Oeste & $0,163^{\star \star \star}$ & $0,161^{\star \star \star}$ & $0,130^{\star \star \star}$ & $0,131^{\star \star \star}$ & $0,116^{\star \star \star}$ \\
\hline Nordeste & $0,704^{\star \star \star}$ & $0,690^{\star \star \star}$ & $0,707^{\star \star \star}$ & $0,691^{\star \star \star}$ & $0,666^{\star \star \star}$ \\
\hline Norte & $0,378^{\star \star \star}$ & $0,372^{\star \star \star}$ & $0,355^{\star \star \star}$ & $0,351^{\star \star \star}$ & $0,329^{\star \star \star}$ \\
\hline Sudeste & $0,162^{\star \star \star}$ & $0,160^{\star \star \star}$ & $0,143^{\star \star \star}$ & $0,136^{\star \star \star}$ & $0,119^{\star \star *}$ \\
\hline \multicolumn{6}{|l|}{ Porte_cidade (ref.: $(0,10$ mil]) } \\
\hline [10 mil, 100 mil] & $-0,037^{\star \star \star}$ & $-0,036^{\star \star \star}$ & $-0,023^{\star \star \star}$ & $-0,027^{\star \star \star}$ & $-0,025^{\star \star \star}$ \\
\hline [100 mil, 1 milhão] & $-0,087^{\star \star \star}$ & $-0,086^{\star \star \star}$ & $-0,066^{\star \star \star}$ & $-0,067^{\star \star \star}$ & $-0,061^{\star \star \star}$ \\
\hline$[1$ milhão,+$]$ & $-0,078^{\star \star \star}$ & $-0,077^{\star \star \star}$ & $-0,055^{\star \star \star}$ & $-0,063^{\star \star \star}$ & $-0,060^{\star * *}$ \\
\hline
\end{tabular}


RAP | Os efeitos do Programa Bolsa Família sobre a duração do emprego formal dos indivíduos de baixa renda

\begin{tabular}{|c|c|c|c|c|c|}
\hline & Exponencial & Weibull & Loglogística & Lognormal & Gamma \\
\hline \multicolumn{6}{|c|}{ Porte_estabelecimento (ref.: $(0,10])$} \\
\hline$[10,100]$ & $-0,356^{\star \star \star}$ & $-0,350^{\star \star \star}$ & $-0,365^{\star \star \star}$ & $-0,364^{\star \star \star}$ & $-0,357^{\star \star \star}$ \\
\hline$[100,1.000]$ & $-0,108^{\star \star \star}$ & $-0,108^{\star \star \star}$ & $-0,045^{\star \star \star}$ & $-0,074^{\star \star \star}$ & $-0,069^{\star \star \star}$ \\
\hline$[1.000,10 \mathrm{mil}]$ & $-0,247^{\star \star \star}$ & $-0,242^{\star \star \star}$ & $-0,262^{\star \star \star}$ & $-0,262^{\star \star \star}$ & $-0,261^{\star \star \star}$ \\
\hline$[10 \mathrm{mil},+]$ & $-0,289^{\star \star \star}$ & $-0,284^{\star \star \star}$ & $-0,307^{\star \star \star}$ & $-0,308^{\star \star \star}$ & $-0,307^{\star \star \star}$ \\
\hline \multicolumn{6}{|c|}{ CBO (ref.: Agropecuária e pesca) } \\
\hline Indústria — generalistas & $0,123^{\star \star \star}$ & $0,120^{\star \star \star}$ & $0,182^{\star \star \star}$ & $0,150^{\star \star \star}$ & $0,148^{\star \star \star}$ \\
\hline Indústria — operadores & $0,076^{\star \star \star}$ & $0,074^{\star \star \star}$ & $0,139^{\star \star \star}$ & $0,115^{\star \star \star}$ & $0,119^{\star \star \star}$ \\
\hline Manutenção e reparação & $0,168^{\star \star \star}$ & $0,164^{\star \star \star}$ & $0,274^{\star \star \star}$ & $0,237^{\star \star \star}$ & $0,243^{\star \star \star}$ \\
\hline Serviço, comércio & $0,232^{\star \star \star}$ & $0,226^{\star \star \star}$ & $0,339^{\star \star \star}$ & $0,308^{\star \star \star}$ & $0,317^{\star \star \star}$ \\
\hline Serviços administrativos & $0,223^{\star \star \star}$ & $0,218^{\star \star \star}$ & $0,352^{\star \star \star}$ & $0,315^{\star \star \star}$ & $0,331^{\star \star \star}$ \\
\hline Técnicos nível médio & $0,182^{\star \star \star}$ & $0,178^{\star \star \star}$ & $0,283^{\star \star \star}$ & $0,245^{\star \star \star}$ & $0,250^{\star \star \star}$ \\
\hline Outros & $0,168^{\star \star \star}$ & $0,165^{\star \star \star}$ & $0,244^{\star \star \star}$ & $0,200^{\star \star \star}$ & $0,200^{\star \star \star}$ \\
\hline \multicolumn{6}{|c|}{ CNAE (ref.: administração pública) } \\
\hline Agricultura, pecuária & $-1,251^{\star * *}$ & $-1,219^{\star \star \star}$ & $-1,077^{\star \star \star}$ & $-0,960^{\star * \star}$ & $-0,861^{\star \star \star}$ \\
\hline Atividades administrativas & $-1,107^{\star \star \star}$ & $-1,077^{\star \star \star}$ & $-1,011^{\star \star \star}$ & $-0,877^{\star \star \star}$ & $-0,793^{\star \star *}$ \\
\hline Comércio e repar. veículos & $-1,383^{\star * \star}$ & $-1,348^{\star \star \star}$ & $-1,226^{\star \star \star}$ & $-1,088^{\star \star \star}$ & $-0,976^{\star \star \star}$ \\
\hline Contração & $-1,674^{\star \star \star}$ & $-1,633^{\star \star \star}$ & $-1,629^{\star \star \star}$ & $-1,449^{\star \star \star}$ & $-1,336^{\star \star \star}$ \\
\hline Indústria & $-1,327^{\star \star \star}$ & $-1,293^{\star \star \star}$ & $-1,131^{\star \star \star}$ & $-0,997^{\star \star \star}$ & $-0,877^{\star \star \star}$ \\
\hline Outros & $-1,341^{\star \star \star}$ & $-1,306^{\star \star \star}$ & $-1,212^{\star \star \star}$ & $-1,074^{\star \star \star}$ & $-0,970^{\star * *}$ \\
\hline constante & $5,490^{\star * \star}$ & $5,501^{\star \star \star}$ & $4,773^{\star \star \star}$ & $4,794^{\star \star \star}$ & $4,630^{\star \star \star}$ \\
\hline Wald chi2 (43) & $84.321^{\star \star \star}$ & $87.453^{\star \star \star}$ & $117.348^{\star \star \star}$ & $105.869^{\star \star \star}$ & $91.278^{\star \star \star}$ \\
\hline AIC & 2.129 .206 & 2.127 .993 & 2.043 .432 & 2.037 .241 & 2.030 .510 \\
\hline $\mathrm{BIC}$ & 2.129 .721 & 2.128 .520 & 2.043 .959 & 2.037 .768 & 2.031 .050 \\
\hline
\end{tabular}

Fonte: Elaborada pelos autores.

Nota: A amostra é composta por todos os admitidos em 2008 e que permaneceram empregados até dezembro de 2011 ou que rescindiram seus contratos com ou sem justa causa e por iniciativa do empregado ou do empregador, considerando as classes de salário de 4 a 7. O número total de observações foi de 909.291, sendo 729.786 indivíduos. O número de falhas foi 565.040. Todos os modelos estão na métrica AFT (aceleração de tempo de falha). p-value: ${ }^{*}<0,10,{ }^{* *}<0,05,{ }^{* * *}<0,01$.

\section{CONCLUSÃO}

Neste artigo analisa-se o efeito do Programa Bolsa Família sobre o emprego formal da parcela pobre da população brasileira, constante do Cadastro Único dos Programas Sociais. A partir de um conjunto de dados único, com mais de 3 milhões de indivíduos, conclui-se que as chances de os beneficiários do Programa Bolsa Família permanecerem no emprego são maiores do que para os não beneficiá- 
rios do programa. Essa constatação não apenas contraria a hipótese de um efeito preguiça vinculado à concessão do benefício, como também estabelece o efeito inverso, de que o benefício financeiro advindo do programa contribua para a manutenção do emprego.

Em termos de políticas públicas, esse é um resultado relevante, uma vez que a população pobre brasileira é caracterizada por considerável volatilidade na renda e rotatividade no emprego, comprometendo os níveis de bem-estar presente e futuro, já que dificulta a obtenção de aposentadorias por tempo de contribuição. Este estudo contribui para a literatura e inova ao analisar o efeito do programa de transferência de renda sobre a duração do emprego, em contraste com a maioria dos estudos que abordaram a questão sob a ótica da participação e da jornada de trabalho (Oliveira e Soares, 2012; Ferro et al., 2010; Chitolina et al., 2016; Foguel e Barros, 2010; Soares, 2012; Tavares, 2010), e ao tratar a presença no Programa Bolsa Família como uma variável tempo-dependente.

Utilizando o modelo semiparamétrico de Cox, estima-se o risco de desligamento do emprego para os beneficiários do Bolsa Família como de 7\% a 10\% menor do que para os não beneficiários. A título de ilustração, pode-se comparar ao efeito causado por filhos menores de idade na composição familiar, que aumentam as chances de os pais deixarem seus empregos. Na regressão principal, a presença de três crianças no lar é responsável por aumentar em 9,6\% a chance de saída do emprego. No entanto, essa probabilidade é anulada se o indivíduo recebe o benefício do PBF. Os modelos paramétricos corroboraram o resultado, indicando que os beneficiários do PBF permanecem, no mínimo, 9\% mais tempo em seus empregos do que os não beneficiários.

Esse efeito descrito está apoiado numa combinação do próprio benefício financeiro, à medida que é usado no cuidado com seus dependentes, com as condicionalidades impostas pelo programa, que exige frequência escolar e visitas aos postos de saúde para as crianças. Desse modo, os resultados apontam para uma prevalência do efeito substituição sobre o efeito renda, fazendo com que o PBF tenha um impacto positivo na manutenção do emprego. 


\section{REFERÊNCIAS}

ALÉM, Ana C.; PASTORIZA, Florinda; GIAMBIAGI, Fabio. A aposentadoria por tempo de serviço no Brasil: estimativa do subsídio recebido pelos seus beneficiários. Revista Brasileira de Economia, v. 52, n. 1, p. 169-206, 1998.

ALZÚA, María L.; CRUCES, Guillermo; RIPANI, Laura. Welfare programs and labor supply in developing countries: experimental evidence from Latin America. Journal of Population Economics, v. 26, n. 4, p. 1255-1284, 2013.

ANTIGO, Mariangela F; MACHADO, Ana F. Transições e duração do desemprego: uma revisão da literatura com novas evidências para Belo Horizonte. Nova Eeconomia, v. 16, n. 3, p. 375-406, 2006.

ARAÚJO, Guilherme S.; RIBEIRO, Rosana; NEDER, Henrique D. Impactos do Programa Bolsa Família sobre o trabalho de crianças e adolescentes residentes na área urbana em 2006. Economia, v. 11, n. 4, p. 57-102, 2010.

BARBOSA, Ana L. N. de H.; CORSEUIL, Carlos H. L. Bolsa Família, escolha ocupacional e informalidade no Brasil. Texto para Discussão, Instituto de Pesquisa Econômica Aplicada (Ipea), 2014.

BARRIENTOS, Armando; VILLA, Juan. Antipoverty transfers and labor force participation effects. BWPI, The University of Manchester, 2013.

BRITO, Alessandra; KERSTENETZKY, Celia L. Programa Bolsa Família e mercado de trabalho: considerações metodológicas e substantivas. AnpecAssociação Nacional dos Centros de Pós-graduação em Economia [Brazilian Association of Graduate Programs in Economics], 2011.

BRITTO, Tatiana. Recent trends in the development agenda of Latin America: an analysis of conditional cash transfers. In: CONFERENCE ON SOCIAL PROTECTION FOR CHRONIC POVERTY HOSTED BY THE INSTITUTE FOR DEVELOPMENT POLICY AND MANAGEMENT AND THE CHRONIC POVERTY RESEARCH CENTRE, 2005, Manchester, United Kingdom. p. 23-24.

CEPAL, N. U. The employment situation in Latin America and the Caribbean: Conditional transfer programmes and the labour market. United Nations Publication, n. 10, 2014.
CHITOLINA, Lia; FOGUEL, Miguel N.; MENEZESFILHO, Naercio A. The impact of the expansion of the Bolsa Família program on the time allocation of youths and their parents. Revista Brasileira de Economia, v. 70, n. 2, p. 183-202, 2016.

DE BRAUW, Alan et al. Bolsa Família and household labor supply. Economic Development and Cultural Change, v. 63, n. 3, p. 423-457, 2015.

DE HOOP, Jacobus; ROSATI, Furio C. Cash transfers and child labor. The World Bank Research Observer, v. 29, n. 2, p. 202-234, 2014.

FERRO, Andrea R.; KASSOUF, Ana L.; LEVISON, Deborah. The impact of conditional cash transfer programs on household work decisions in Brazil. In: AKEE, Randall K.Q.; EDMONDS, Eric V.; TATSIRAMOS, Konstantinos (Ed.). Child labor and the transition between school and work. Research in Labor Economics, v. 31, p. 193-218, 2010.

FOGUEL, Miguel N.; BARROS, Ricardo P. de. The effects of conditional cash transfer programmes on adult labour supply: an empirical analysis using a time-series-cross-section sample of Brazilian municipalities. Estudos Econômicos, São Paulo, v. 40, n. 2, p. 259-293, 2010.

GARCIA, Carlos H.; DEDECCA, Claudio S. A heterogeneidade do mercado de trabalho e a desigualdade na representação sindical. Sociologia \& Antropologia, v. 3, n. 5, p. 223-243, 2013.

GIAMBIAGI, Fabio; AFONSO, Luís E. Cálculo da alíquota de contribuição previdenciária atuarialmente equilibrada: uma aplicação ao caso brasileiro. Revista Brasileira de Economia, v. 63, n. 2, p. 153-179, 2009.

GONZALEZ-ROZADA, Martin; PINTO, Freddy L. The effects of a conditional transfer program on the labor market: the human development bonus in Ecuador. Washington, DC: Inter-American Development Bank, 2011. Mimeografado.

KLEINBAUM, David G.; KLEIN, Mitchel. Survival analysis: a self-learning text. Nova York: Springer Science \& Business Media, 2006.

LANCASTER, Tony. The econometric analysis of transition data. Nova York: Cambridge University Press, 1992. 
LEICHSENRING, Alexandre R. Precariedade laboral e o Programa Bolsa Família. In: De CASTRO, Jorge A.; MODESTO, Lúcia. Bolsa Família 20032010: avanços e desafios. Brasília: Ipea, 2010. v. 1, p. 271-300.

LINDERT, Kathy et al. The nuts and bolts of Brazil's Bolsa Família program: implementing conditional cash transfers in a decentralized context. Social Protection Discussion Paper, 2007.

LIRA, Sachiko A. Duração do desemprego na região metropolitana de Curitiba. Revista Paranaense de Desenvolvimento-RPD, n. 109, p. 139-160, 2011.

MALBOUISSON, Cláudia Sá; MENEZES, Wilson F. Duração do desemprego na Região Metropolitana de Salvador: mensuração e análise. In: ENCONTRO NACIONAL DE ECONOMIA, 32, João Pessoa, PB. Anais... João Pessoa: Anpec, 2004.

MARSHALL, Caroline; HILL, Peter S. Ten best resources on conditional cash transfers. Health Policy and Planning, v. 30, n. 6, p. 742-746, 2014.

MEDEIROS, Marcelo; BRITTO, Tatiana; SOARES, Fabio. Programas focalizados de transferência de renda: contribuições para o debate. Ipea, Texto para discussão n. 1283, Brasília, jun. 2007.

MENEZES, Wilson F.; DEDECCA, Cláudio S. Avaliação da duração do desemprego nas regiões metropolitanas de Salvador e de São Paulo. Revista Economia Contemporânea, v. 10, n. 1, p. 35-60, 2006.

MENEZES-FILHO, Naércio A. et al. Trade unions and the economic performance of Brazilian establishments. Estudos Econômicos, v. 38, n. 1, p. 55-72, 2008.

MENEZES-FILHO, Naércio A.; PICCHETTI, Paulo. Os determinantes da duração do desemprego em São Paulo. Pesquisa e Planejamento Econômico, v. 30, n. 1, p. 23-47, 2000.

OLIVEIRA, Ana M. H. et al. The first results of the baseline impact evaluation of Bolsa Família. In: VAITSMAN, Jeni; PAES-SOUZA, Rômulo (Ed.). Evaluation of MDS' programs and policies-results. Brasília: Sagi/MDS, 2007. v. 2, p. 19-64.

OLIVEIRA, Luis F. B.; SOARES, Sergei S. D. O que se sabe sobre os efeitos das transferências de renda sobre a oferta de trabalho. Texto para Discussão,
Instituto de Pesquisa Econômica Aplicada (Ipea), 2012.

OLIVEIRA, Paulo F. A. de; CARVALHO JÚNIOR, José R. de A. Desigualdade de gênero na duração do desemprego e seus efeitos sobre os salários aceitos no Brasil. Revista Econômica do Nordeste, v. 40, n. 4, p. 833-850, 2009.

PARKER, Susan; SKOUFIAS, Emmanuel. The impact of Progresa on work, leisure and time allocation. Washington, DC: International Food Policy Research Institute, 2000.

PENIDO, Mariângela; MACHADO, Ana. Desemprego: evidências da duração no Brasil metropolitano. In: ENCONTRO DA ASSOCIAÇÃO BRASILEIRA DE ESTUDOS POPULACIONAIS - ABEP, XIII, 2002, Ouro Preto.

SKOUFIAS, Emmanuel; DI MARO, Vincenzo. Conditional cash transfers, adult work incentives, and poverty. The Journal of Development Studies, v. 44, n. 7, p. 935-960, 2008.

SOARES, Fábio V.; RIBAS, Rafael P. Is the effect of conditional transfers on labor supply negligible everywhere? In: IZA/WORLD BANK CONFERENCE: EMPLOYMENT AND DEVELOPMENT, $6^{\text {th }}$, 2011, Cidade do México.

SOARES, Fábio V.; RIBAS, Rafael P.; OSÓRIO, Rafael G. Evaluating the impact of Brazil's Bolsa Família: Cash transfer programs in comparative perspective. Latin American Research Review, v. 45, n. 2, p. 173-190, 2010.

SOARES, Sergei S. D. Bolsa Família, its design, its impacts and possibilities for the future. Working Paper 89, International Policy Centre for Inclusive Growth, 2012.

TAVARES, Priscilla A. Efeito do Programa Bolsa Família sobre a oferta de trabalho das mães. Revista Economia e Sociedade, v. 19, n. 3, p. 613-635, 2010.

TEIXEIRA, Clarissa G. A heterogeneity analysis of the Bolsa Familía Programme effect on men and women's work supply. Working Paper, International Policy Centre for Inclusive Growth, 2010.

WOOLDRIDGE, Jeffrey M. Econometric analysis of cross section and panel data. Cambridge: MIT Press, 2010. 
RAP | Os efeitos do Programa Bolsa Família sobre a duração do emprego formal dos indivíduos de baixa renda

\section{Danilo Braun Santos}

Doutor em administração de empresas pela Fundação Getulio Vargas (EAESP) e professor da Universidade Federal de São Paulo/Escola Paulista de Política, Economia e Negócios. E-mail: danilo.braun@unifesp.br.

\section{Alexandre Ribeiro Leichsenring}

Universidade de São Paulo/Escola de Artes, Ciências e Humanidades. E-mail: alexandre.leichsenring@usp.br.

\section{Naercio Menezes Filho}

Insper Instituto de Ensino e Pesquisa e Universidade de São Paulo/Departamento de Economia. E-mail: NaercioAMF@insper.edu.br.

\section{Wesley Mendes-Da-Silva}

Fundação Getulio Vargas/Escola de Administração de Empresas de São Paulo. E-mail: mr.mendesdasilva@ gmail.com. 